\title{
Agriculture 2.0: Light Emitting Diode (LED), Light Quality, and Crop Production in Controlled Environment Facilities
}

\section{Luca Vitale*}

National Research Council, Institute for Agricultural and Forestry Systems in the Mediterranean, Ercolano, Italy

*Corresponding Author: Luca Vitale, National Research Council, Institute for Agricultural and Forestry Systems in the Mediterranean, Ercolano, Italy.

Received: July 02, 2019; Published: July 16, 2019

DOI: 10.31080/ASAG.2019.03.0577

Light conditions such as intensity, photoperiod, and quality are the major light factors affecting plant growth and these factors may be managed using artificial light sources. Among these, Light Emitting Diode (LED) technology is becoming one of the most promising approaches as artificial light source for crops production in controlled environment facilities (CEFs). Many are advantages of LED over traditional forms of lighting including high luminous efficiency, reduced energy consumption and cost, and low heat production [1]. Moreover, the LED light systems allow managing the light spectrum composition defining specific light regimes useful for plant growth and development.

Light quality affects plant growth influencing its anatomy, morphology, and physiology [2]; moreover, light quality affects the production of secondary metabolites such as polyphenols (e.g. phenols, flavonoids, anthocyanins, etc.) and other antioxidant compounds (e.g. ascorbic acid, tocopherols, carotenoids, etc.) that have prized effects on human health. Therefore, the appropriate combination of wavelengths (i.e. red, blue, and green) can enhance the plant biomass production as well as the bioactive compounds production, also improving the nutraceutical properties of some crop species.

\section{Bibliography}

1. LG Izzo., et al. "Light quality shapes morpho-functional traits and pigment content of green and red leaf cultivars of Atriplex hortensis". Scientia Horticulturae 246 (2019): 942-950.

2. L Zheng and Van MC Labeke. "Long-term effects of red- and blue-light emitting diodes on leaf anatomy and photosynthetic efficiency of three ornamental pot Plants". Frontiers in Plant Sciences 8 (2017): 917.

\section{Volume 3 Issue 8 August 2019 (C) All rights are reserved by Luca Vitale.}

